\title{
SELECTED PROPERTIES OF HYBRID PTA-MAG WELDED JOINTS OF THERMOMECHANICALLY ROLLED S700MC STEEL
}

\author{
Beata SKOWROŃSKA, Tomasz CHMIELEWSKI, Tadeusz SAŁACIŃSKI, Jacek SZULC, \\ Rafał ŚWIERCZ \\ Institute of Manufacturing Technologies, Warsaw University of Technology, Warsaw, Poland, EU, \\ beata.skowronska@pw.edu.pl
}

https://doi.org/10.37904/metal.2020.3506

\begin{abstract}
The aim of this paper is to describe the selected mechanical properties and microstructure of butt welded joints obtained by the hybrid Plasma+MAG method of $S 700 \mathrm{MC}$ steel (high strength $\mathrm{Re}=700 \mathrm{MPa}$ ). The results of metallographic research of welded joints, microstructure of the weld and heat affected zone, hardness distribution and impact toughness are presented. The tensile test shown that strength of welded joints was slightly reduced and the bending test revealed no crack formation in the weld. The impact toughness of measured welded samples with V-notch in HAZ (heat affected zone) reached high values that are higher comparing to samples with notch placed in the weld area. The investigation results show that the use of hybrid plasma + MAG welding arc does not significantly change the structure and deteriorate properties of welded S700MC thermomechanically treated high strength steel.
\end{abstract}

Keywords: Hybrid welding, microstructure, mechanical properties, welded joints, high strength steel

\section{INTRODUCTION}

The dynamic development of welding processes has led to the development of new varieties of hybrid welding, usually combining two welding methods with different heat sources: arc welding with concentrated energy beam welding, e.g. laser. In this process, the temperature field is created by the simultaneous interaction of an electric arc and a laser beam. An example of hybrid welding is most often a combination of the laser welding method with the MAG (Metal Active Gas) method [1] or the TIG (Tungsten Inert Gas) method [2]. This paper concerns hybrid welding based on a combination of concentrated plasma arc and MAG [3], which strengthens the advantages of both methods and simultaneously reduces the limitations. On the one hand, the heat source in the form of high-energy plasma ensures deep penetration of the steam channel, and the classic GMA heat source fills the welding groove. This combination significantly increases welding efficiency, reduces binder consumption, and most importantly, reduces the need for precise edge preparation for the welding process, which is very important in industrial conditions. Hybrid plasma welding is from investment and operational point of view a much cheaper solution compared to that in which it is based on a laser. This innovative plasma welding method+GMA requires the use of a special magnetic curtain, thanks to which the current of both the plasma arc and the GMA arc flows through the welded material. Otherwise, they would endure each other because of the opposite polarity [4]. The described method combines the MAG (Metal Active Gas) arc welding process and the plasma welding method to increase the welding performance. The purpose of the plasma application is to achieve deep penetration (opened evaporation canal - keyhole) in welded material. The creation of an evaporation channel is possible when the plasma arc's density is above $1010 \mathrm{~W} / \mathrm{m}^{2}$. The role of the MAG method is to fill the opened channel with the weld metal and create the suitable shape of the face of a weld. The hybrid welding process uses many advantages of both welding heat sources. The hybrid welds can have deep penetration level, comparable with depths obtained by plasma key-hole welding, but at the same time having a tolerance of joints fit-up and weld cap profile more comparable with MAG welds. In general, 
the hybrid welding system is characterized by an extremely high welding efficiency, measured by the mass of fused metal. It has approximately up to 20 times higher welding efficiency compared to conventional welding methods. It can be assumed that one bead welded by the hybrid plasma+MAG method corresponds to 5 beads produced by the classic welding method. A similar relation exists in relation to welding speed, which achieve much higher values for the hybrid method. Schematic drawing of the hybrid plasmatron is presented in Figue 1. The construction of the hybrid system and its technological properties can be found in literature [4].
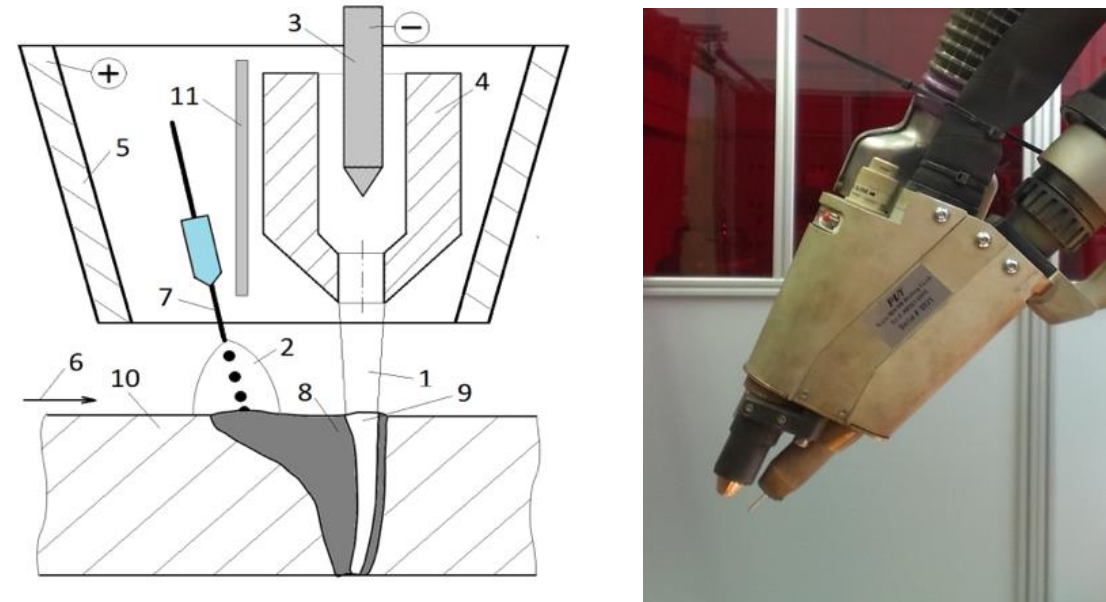

Figure 1 Hybrid plasmatron: a) Schematic drawing, 1 - plasma arc, 2 - MAG arc, 3 - plasmatron cathode, 4 - plasma nozzle, 5 - shielding gas nozzle, 6 - welding direction, 7 - MAG wire electrode, 8 - liquid metal, 9 - plasma keyhole, 10 - welded material, 11 - magnetic curtain; b) general view

The S700MC steel is an attractive construction material with quite simple mechanical composition. It belongs to a group of high strength steels (HSS) which are subjected to thermomechanical treatment in the production process that provides it with high strength properties. On the other hand, it is also sensitive to heat and reacts to it through excessive recrystallization, which weakens the heat affected zone (HAZ). For such materials the use of hybrid welding methods based on plasma or laser beam should be adequate to reduce the amount of heat introduced into the joint and thus limit the unfavourable changes that may occur in HAZ, due to too much heat introduced.

\section{HYBRID PLASMA + MAG WELDING PROCESS}

The welding abilities of S700MC HSS steel is generally pretty good. The significant problem when welding S700MC steel is the presence of high-temperature coarse grains in the heat affected zone (HAZ). A rapid decrease of impact toughness in this region is observed due to the nucleation effect of the dissolved phases, strengthening the matrix and their subsequent uncontrolled separation and precipitation in the form of finely dispersion phases.

Table 1 Chemical composition and mechanical properties of S700MC steel

\begin{tabular}{|c|c|c|c|c|c|c|c|c|c|c|c|}
\hline \multicolumn{12}{|c|}{ Chemical composition, wt $\%$} \\
\hline C & $\mathrm{Si}$ & $\mathrm{Mn}$ & $\mathrm{P}$ & $\mathrm{S}$ & $\mathrm{Al}$ & $\mathrm{Nb}$ & $\mathrm{V}$ & $\mathrm{Ti}$ & $\mathrm{B}$ & Mo & C equivalent \\
\hline 0.059 & 0.253 & 1.912 & 0.009 & 0.006 & 0.027 & 0.057 & 0.021 & 0.087 & 0.087 & 0.106 & 0.33 \\
\hline \multicolumn{12}{|c|}{ Mechanical properties } \\
\hline \multicolumn{3}{|c|}{$\begin{array}{c}\text { Tensile strength } \\
\text { Rm (MPa) }\end{array}$} & \multicolumn{3}{|c|}{$\begin{array}{c}\text { Yield stress } \\
\operatorname{Re}(\mathrm{MPa})\end{array}$} & \multicolumn{2}{|c|}{$\begin{array}{c}\text { Elongation } \\
\text { A5 }(\%)\end{array}$} & \multicolumn{2}{|c|}{$\begin{array}{c}\text { Hardness } \\
\text { HV }\end{array}$} & \multicolumn{2}{|r|}{$\begin{array}{l}\text { Impact strength } \\
\mathrm{J} / \mathrm{cm}^{2}\left(-20^{\circ} \mathrm{C}\right)\end{array}$} \\
\hline \multicolumn{3}{|c|}{830} & \multicolumn{3}{|c|}{767} & \multicolumn{2}{|c|}{19} & \multicolumn{2}{|c|}{280} & \multicolumn{2}{|r|}{135} \\
\hline
\end{tabular}


Table 2 Chemical composition of G 696 M21 Mn4Ni1 filler material

\begin{tabular}{|c|c|c|c|c|c|c|}
\hline \multicolumn{7}{|c|}{ Chemical composition, wt\% } \\
\hline $\mathrm{C}$ & $\mathrm{Si}$ & $\mathrm{Mn}$ & $\mathrm{Cr}$ & $\mathrm{Ni}$ & $\mathrm{Mo}$ & $\mathrm{Ti}$ \\
\hline 0.09 & 0.55 & 1.67 & 0.25 & 1.52 & 0.50 & 0.07 \\
\hline
\end{tabular}

The plasma+MAG hybrid weld- ing tests that have been taken here have shown that in order to ensure high quality of welded joints it is necessary to limit the welding linear energy input. During the welding process of S700MC steel, it is not recommended to use both preheating and post welding heat treatment operations. Due to high strength properties of S700MC steel it is necessary to try to limit the amount of heat introduced into the material in the welding process, which will have a destructive effect on the properties obtained in the thermomechanical process of steel production. Recrystallization processes developed in HAZ will lead to softening of the material and loss of the initially high strength properties of steel. Also, the welding thermal cycle promotes the solution of fine-dispersive carbides, $\mathrm{Nb}$, Ti and $\mathrm{V}$ and their uncontrolled precipitation again $[1,2]$. This may affect the phase transformation in HAZ during cooling and also during post-weld heat treatment which will lead to reduction of impact toughness [5]. Introduction a large amount of heat into the welded S700 steel extends the time of holding the HAZ at elevated temperature and lowers its cooling time, which makes the austenite grains to grow and formation of structures that have limited plasticity [6]. Hence, both preheating and heat treatment after welding will further promote recrystallization in HAZ and reduce the original mechanical properties [7]. To study the properties and weldability of S700MC steel welded by the plasma+MAG hybrid system, samples of $10 \mathrm{~mm}$ thick steel S700MC sheets were prepared for butt joints. The sheets were welded in the flat position on a water-cooled copper backing strip using solid filler wire G69 6 M21 Mn4Ni1 with a diameter of $1.2 \mathrm{~mm}$. The chemical composition and the mechanical properties of the S700MC steel used are shown in Table 1. These data were taken from the manufacturer's (SSAB) certifi- cate of supplied Domex 700MC E steel. The microstructure of S700MC steel is presented in Figure 2. The material has a bainitic-ferritic structure with a visible effect of plastic deformation resulting from the thermomechanical treatment process. For the hybrid welding a filler wire G 696 M21 Mn4Ni1 (ED-FK 800) with 1.2 mm diameter was used. This material is dedicated to welding of high strength low alloy steel [8,9]. It was selected for hybrid welding of S700MC steel due to its high yield stress (above $690 \mathrm{MPa}$ ) which is comparable with the base material. The chemical composition of the filler wire metal is collected from the manufacturer's (Fliess) data sheet and is presented in Table 2. The hybrid plasma+MAG welding was performed using PLT Hybrid SuperMIG system. The welding plasmatron was mounted in a wrist of industrial KUKA KR 16-2f robot. The hybrid welding parameters are presented in Table 3. The plasma gas used in test was $\operatorname{Ar} 100 \%$ and the shielding gas used in the test was mixture $\left(18 \% \mathrm{CO}_{2}+82 \% \mathrm{Ar}\right)$, whereas the gas flow rate amounted to $22 \mathrm{dm}^{3} / \mathrm{min}$. The welding process was carried out using one pass. The parameters used during making the butt joints and other welding conditions (adjusted on the basis of preliminary test) are presented in Table 3.

Table 3 Parameters of the hybrid butt welding of $10 \mathrm{~mm}$ thickness steel S700MC

\begin{tabular}{|c|c|c|c|c|c|c|}
\hline $\begin{array}{c}\text { Plasma arc } \\
\text { voltage, } \mathrm{V}\end{array}$ & $\begin{array}{c}\text { Plasma arc } \\
\text { current, A }\end{array}$ & $\begin{array}{c}\text { MAG arc } \\
\text { voltage, } \mathrm{V}\end{array}$ & $\begin{array}{c}\text { MAG arc } \\
\text { current, A }\end{array}$ & $\begin{array}{c}\text { Travel speed } \\
\mathrm{m} / \mathrm{min} .\end{array}$ & $\begin{array}{c}\text { Heat input } \\
\mathrm{KJ} / \mathrm{mm}\end{array}$ & $\mathrm{Ti}$ \\
\hline 23.9 & 332.4 & 33.6 & 390.7 & 0.95 & 0.96 & 0.07 \\
\hline
\end{tabular}

\section{INVESTIGATION RESULTS}

Hybrid welded joints were prepared for testing by cleaning the surface in accordance with the procedure described in the literature. Welded joints were tested by visual examination and by the magnetic particle test which did not reveal shape and surface welding imperfections. The welded joints satisfied the requirements related to quality level B according to ISO 12932. The microscopic observations did not show the presence of welding imperfections both in weld and in the heat affected zone (Figure 2). The shape and dimension of weld 
root reflected the shape and dimensions of the copper backing strip used during welding. We may distinguish double HAZ in the joint. This probably results from the fact that in the hybrid welding process we have almost simultaneous interaction of two arcs (plasma and classical arc) with significantly different heat concentration densities. The heating mechanism is different in both heat sources (the plasma arc creates a 'keyhole' gas channel, while the classic arc creates a liquid weld pool and the heat is transferred based on conduction). Both arches interact to some extent (overlap) and with significantly different amount of heat introduced into the material, a characteristic HAZ is created containing two different subzones. The microscopic observations revealed a bainitic- ferritic microstructure in the weld area. The structure of the base material is characterized by a banded grain arrangement with visible plastic deformation resulting from the production process of S700MC grade steel which is based on controlled rolling with accelerated cooling. This effect, due to the high temperature of the welding process, was lost in HAZ2 (fine-grained structure), while in HAZ1, in the hightemperature area, significant grain growth occurred.

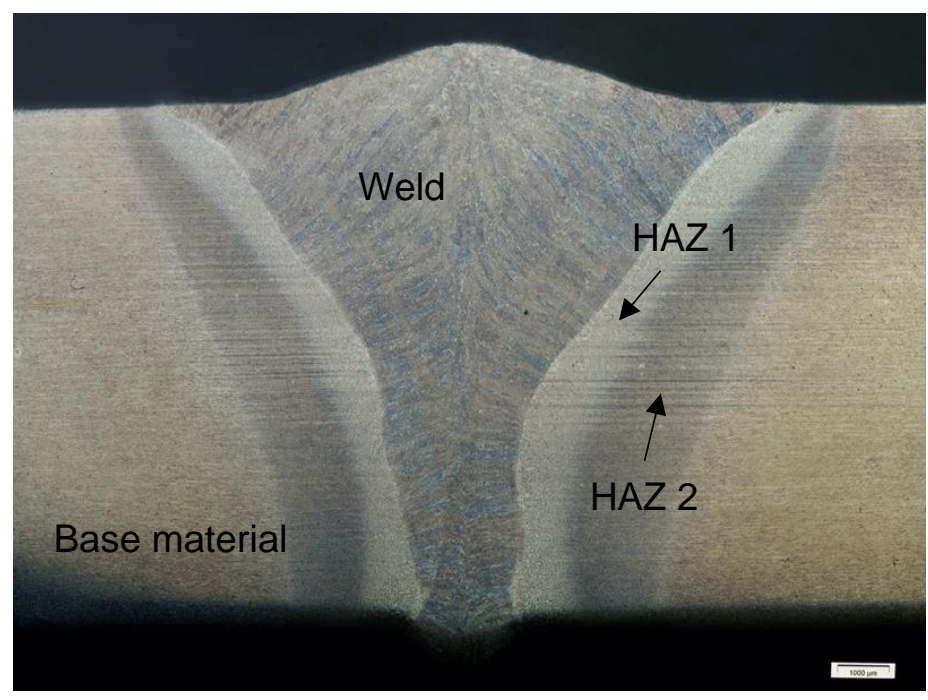

Figure 2 Microstructure of the hybrid plasma + MAG welded joints made of S700MC steel

Further mechanical tests of the S700MC hybrid welded joints were carried out tensile strength, bending tests of joints from the face and root side, and impact tests. The tensile tests were carried out in accordance with requirements of the EN-ISO 15614-14 standard. The sample size and dimensions are presented in Figure 3. The hybrid plasma + MAG welding process resulted in a slight decrease of tensile strength (approx. $\mathrm{Rm}=770$ $\mathrm{MPa}$ in all tested samples) from $820 \mathrm{MPa}$ of the base material. The fracture took place in the weld area for all tested samples. The amount of base material in the weld is at a level exceeding $50 \%$ thus, the chemical composition of the weld may have been significantly reduced. The tensile strength of the applied filler metal equals to $770 \mathrm{MPa}$, so improvement of joint's tensile strength can be achieved, e.g. by choosing a different one filler material.

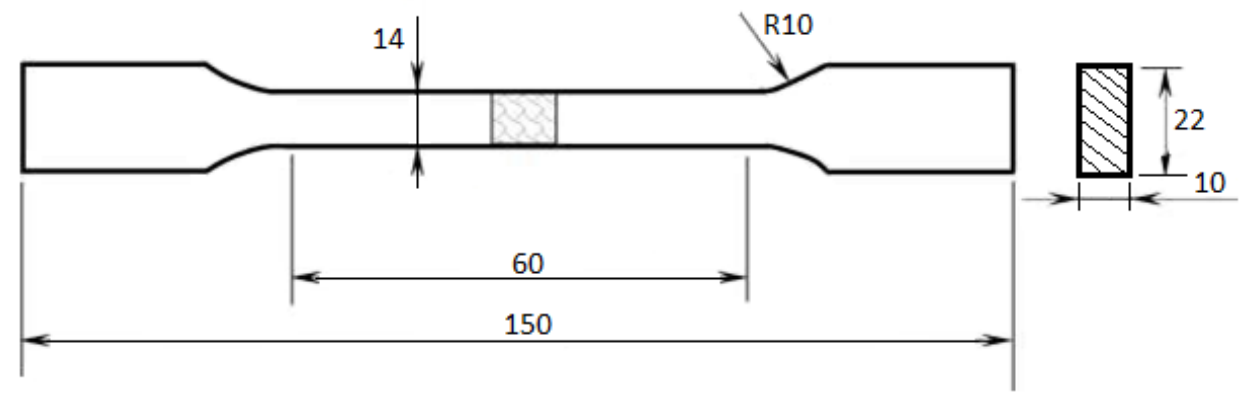

Figure 3 Geometry of welded samples used in tensile tests 
The bending tests were performed according to PN-EN ISO 5173:2010. The three point bending was performed on the machine with maximal force of $F=50 \mathrm{kN}$. The loading with a pin roll of $15 \mathrm{~mm}$ radius was performed on samples both from the face and root sides. The results show no failure up to the maximum loading force, which demonstrated high plastic properties of the joint. The Charpy impact test was performed at the temperature of $-30^{\circ} \mathrm{C}$ according to PN-EN 10045-1:1994 on welded samples with v-notch located in the weld and in the HAZ. The VEB Werkstoffprüfmachinen Leipzig impact testing machine was used with initial impact energy of $300 \mathrm{~J}$. The obtained results presented satisfactory impact toughness values in the weld, fusion line, and in the HAZ. It is noteworthy that in all tested joints the impact toughness was higher in the samples with notch located in HAZ in contrast to a notch in weld area. In sample of welded joint it was 169 $\mathrm{J} / \mathrm{cm} 2$ with a notch in HAZ and $99 \mathrm{~J} / \mathrm{cm} 2$ with a notch in weld. The higher impact toughness observed for samples with notch located in HAZ is reflected by the fact that they were not completely divided by the impact energy. One of the reasons for such results may be a double heat cycle and two sub-zones developed in HAZ. Basing on the view of fractured surfaces of tested joints we may say that fractured samples with notch located in the HAZ presents mixed mode of fracture described by delamination and ductile type Figure 4. On the other hand, the samples with notch in the weld present brittle type of fracture and the microstructure of fractured samples is characterized by fine grains.

a)

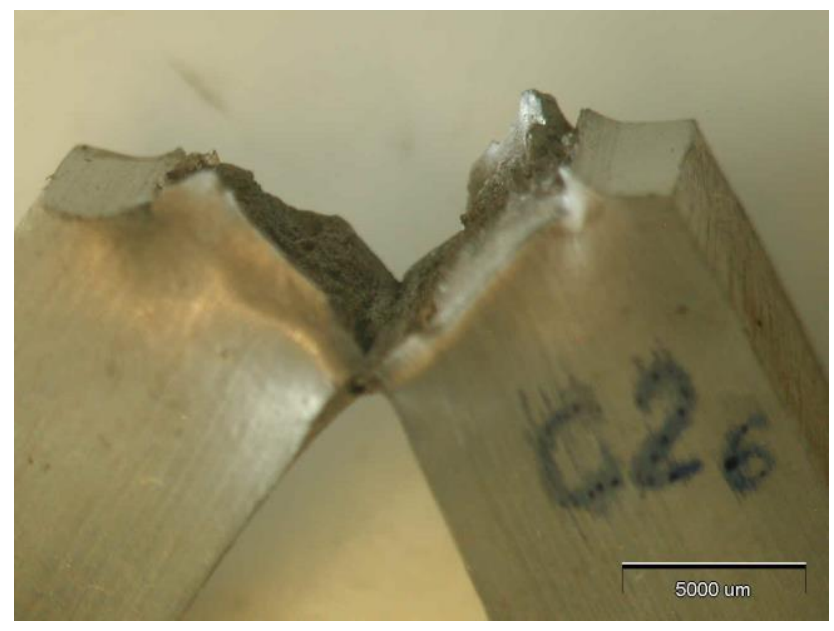

b)

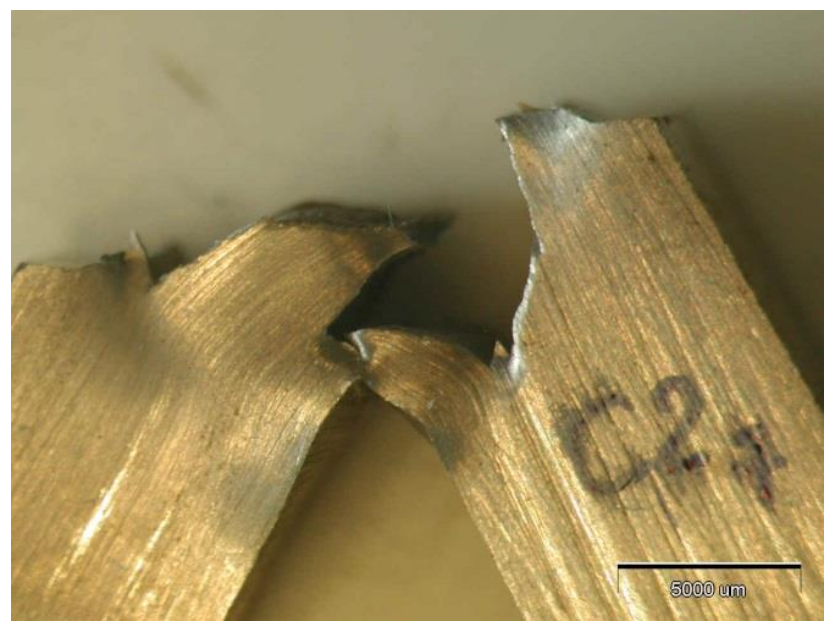

Figure 4 Fractured area of hybrid plasma+MAG welded joints: a) notch in weld, b) notch in HAZ

The collected results from mechanical testing of hybrid welded joints for samples A and B are presented in Table 4. The mechanical testing was conducted using a series of four samples in each test.

Table 4 Results of tensile, bending and Charpy impact test carried out on samples produced by hybrid plasma+MAG welding

\begin{tabular}{|c|c|c|c|c|}
\hline Mechanical test & - & $\begin{array}{c}\text { Average force, } \\
\mathrm{kN}\end{array}$ & $\begin{array}{c}\text { Standard deviation, } \\
\mathrm{kN}\end{array}$ & $\begin{array}{c}\text { Average ultimate tensile strength, } \\
\mathrm{MPa}\end{array}$ \\
\hline Tensile & - & 108 & 1.37 & 771.4 \\
\hline Bending & $\begin{array}{c}\text { Bending } \\
\text { angle } 180^{\circ}\end{array}$ & & & \\
\hline & - & $\begin{array}{c}\text { Average impact } \\
\text { energy, J }\end{array}$ & $\begin{array}{c}\text { Standard deviation, } \\
\mathrm{J}\end{array}$ & $\begin{array}{c}\text { Average impact toughness at }-30^{\circ} \mathrm{C}, \\
\mathrm{J}^{2} \mathrm{~cm}^{2}\end{array}$ \\
\hline \multirow{2}{*}{ Impact } & Weld & $\begin{array}{c}79 \\
135\end{array}$ & $\begin{array}{c}11.10 \\
90.59\end{array}$ \\
\hline
\end{tabular}




\section{CONCLUSIONS}

To sum up, the conducted research allows drawing the following conclusions:

- In the heat-affected zone, two subzones HAZ1 and HAZ2 can be distinguished, differing in microstructure and hardness. In the HAZ1, significant grain growth occurred accompanied by lowered microhardness.

- It is possible to make correct weld with the required quality and properties of single-pass welded $(10 \mathrm{~mm})$ joint of S700MC steel with the hybrid plasma + MAG method.

- $\quad$ The decrease in the average hardness in the joint depends on the linear welding energy - the joint made with a lower energy input was characterized by a smaller hardness decrease.

- $\quad$ The impact toughness at the temperature of $-30{ }^{\circ} \mathrm{C}$ measured in samples with notch in $\mathrm{HAZ}$ reaches very high values. This may be the result of a double heat cycle and a two-zone area formed in HAZ.

The results presented in this paper broaden the knowledge about welding of S700MC high strength steel using hybrid plasma+MAG method. The use of steel with high yield strength allows both a reduction in the weight of the structure and the consumption of steel. The application of an innovative hybrid plasma+MAG welding method has a potential to become a beneficial alternative to other welding processes (including hybrid laser+GMA) due to its high efficiency, reduced the amount of weld metal content or limited requirements for precise preparation of the joint edges. Also, the investiga- tion results show that the use of plasma concentrated heat source together with MAG welding arc does not significantly change the structure and deteriorate properties of welded S700MC thermomechanically treated high strength steel.

\section{REFERENCES}

[1] GÓRKA, J. Weldability of Thermomechanically Treated Steels Having a High Yield Point. Archives of Metallurgy and Materials. 2015, vol. 60, no. 1, pp. 469-475.

[2] GÓRKA, J. Study of structural changes in S700MC steel thermomechanically treated under the influence of simulated welding thermal cycles. Indian Journal of Engineering and Materials Sciences. 2015, vol. 22, pp. 497502.

[3] GÓRKA, J. Welding Thermal Cycle-Triggered Pre. Archives of Metallurgy and Materials. 2017, vol. 62, no. 1, pp. 321-326.

[4] SKOWROŃSKA, B., CHMIELEWSKI, T., GOLAŃSKI, D., SZULC, J. Weldability of S700MC steel welded with the hybrid plasma + MAG method. Manufacturing Review. 2020, vol. 7, no. 4, pp. 152-159.

[5] SALACINSKI, T., CHMIELEWSKI, T., WINIARSKI, M., CACKO, R., ŚWIERCZ, R. Roughness of metal Surface after finishing using ceramic brush tools. Advances in Materials Science. 2018, vol. 18, no. 1, pp. 20-27.

[6] IWASZKO, J., KUDŁA K., FILA K., Friction stir processing of the AZ91 magnesium alloy with SiC particles. Archives of Materials Science and Engineering. 2016, vol. 77, no. 2, pp. 85-92.

[7] SKOWROŃSKA, B., CHMIELEWSKI, T., PACHLA, W., KULCZYK, M., SKIBA, J., PRESZ, W., Friction weldabillity of UFG 316L stainless steel. Archives of Metallurgy and Materials. 2019, vol. 64, no. 3, pp. 10511058.

[8] FYDRYCH, D., ŁABANOWSKI, J., ROGALSKI, G., HARAS, J., TOMKÓW, J., ŚWIERCZYŃSKA, A, JAKÓBCZAK, P., KOSTRO, Ł., Weldability of S500MC steel in underwater conditions. Advances in Materials Science. 2014, vol. 14, no. 2, pp. 37-45.

[9] FYDRYCH, D., ŁABANOWSKI, J., TOMKÓW, J., ROGALSKI, G., Cold Cracking of Underwater Wet Welded S355G10+N High Strength Steel. Advances in Materials Science. 2015, vol. 15, no. 3, pp. 48-56.. 